\title{
¿Signals of Spring Thermal Contrast Related to the Interannual Variations in the Onset of the South China Sea Summer Monsoon
}

\author{
YANA LI \\ School of Atmospheric Sciences, Sun Yat-sen University, Guangzhou, China
}

SONG YANG

School of Atmospheric Sciences, and Guangdong Province Key Laboratory for Climate Change and Natural Disaster Studies, Sun Yat-sen University, Guangzhou, and Southern Marine Science and Engineering Guangdong

Laboratory, Zhuhai, China

YI DENG

School of Earth and Atmospheric Sciences, Georgia Institute of Technology, Atlanta, Georgia

\author{
BIN ZHENG
}

Guangzhou Institute of Tropical and Marine Meteorology, China Meteorological Administration, Guangzhou, China

(Manuscript received 2 March 2019, in final form 5 July 2019)

\begin{abstract}
Land-sea thermal contrast is one of the key factors modulating the onset and strength of summer monsoons. This study investigates the precursory thermal-contrast signal of the onset of the South China Sea summer monsoon (SCSSM) and reveals that the land-sea thermal contrast $D T$ ( $T_{\text {ocean }}$ minus $T_{\text {land }}$ at the surface) in March tracks the date of the monsoon onset very well. In an energy-balance framework, the monthly anomalies in this thermal contrast are decomposed into different components associated with the anomalies of various radiative and nonradiative dynamical processes over the South China Sea in early spring. It is found that the interannual variations of $D T$, and thus the onset date of monsoon, are mainly tied to the anomalies in surface heat fluxes, ocean-land heat storage rate, and oceanic dynamical processes. The variation of ocean-land heat storage rate and ocean dynamics is the largest positive contributor to the change in DT. Specifically, an early SCSSM onset tends to be associated with an amplified "cold-land, warm-ocean" pattern that can be further attributed to increased soil moisture content in March, which enhances land surface cooling and weakens oceanic heat storage rate that benefits ocean surface warming. Furthermore, the variations of $D T$ and soil moisture content in March are positively related with the late-February precipitation over the Indochina Peninsula, which could therefore be regarded as a precursory signal for both the land-sea thermal contrast in March and the onset of the SCSSM.
\end{abstract}

\section{Introduction}

The onset of the South China Sea (SCS) summer monsoon (SCSSM) occurs around mid- to late May (Lau and Yang 1997), which is characterized by an abrupt increase in precipitation and regarded as the commencement of the East Asian summer monsoon (Tao

¿ Denotes content that is immediately available upon publication as open access.

Corresponding author: Song Yang, yangsong3@mail.sysu.edu.cn and Chen 1987; Ding and Chan 2005). In contrast to the relatively "punctual" onset of the Indian summer monsoon, the onset of the SCSSM exhibits considerable year-to-year variation (Wu and Wang 2001; Ha et al. 2012). The onset time has been measured by indices of different types of variables, such as precipitation (Wang and LinHo 2002), low-level or surface winds (Yan 1997; Wang et al. 2004), low-level meridional wind ( $\mathrm{Lu}$ and Chan 1999), vertical zonal wind shear ( $\mathrm{Li}$ and $\mathrm{Wu} 2000$ ), equivalent potential temperature (Gao et al. 2001), and meridional temperature gradient (Liu et al. 2016). In operation, the SCSSM onset time is defined by the 
National Climate Center, China Meteorological Administration, as the pentad when the $850-\mathrm{hPa}$ winds switch to westerly wind and the $850-\mathrm{hPa}$ saturation equivalent potential temperature arises above $340 \mathrm{~K}$ over $10^{\circ}-20^{\circ} \mathrm{N}, 110^{\circ}-120^{\circ} \mathrm{E}$ (https://cmdp.ncc-cma.net/ Monitoring/monsoon.php?ListElem $=p 8$ ciu). All of these indices can capture a certain aspect of the SCSSM onset on pentad time scales prior to the onset. An early (a late) onset matches a strong (weak) SCSSM (Zhou et al. 2005). A strong (weak) SCSSM usually leads to less (more) precipitation over the middle and lower reaches of the Yangtze River basin, but more (less) precipitation in North China (Ding et al. 2004; He and Zhu 2015). Therefore, investigating the interannual variation and exploring predictors for the SCSSM onset on the monthly to seasonal time scales are important to gain insights into the monsoon dynamics.

Previous studies have revealed three key mechanisms of the SCSSM onset. The first mechanism is relevant to the intraseasonal oscillation (ISO). When the 10-20-day ISO from the Indian summer monsoon region and the 30-60-day ISO from the monsoon trough propagate to the SCS, the onset starts with considerable increase in precipitation (Chen and Chen 1995; Mao and Chan 2005; Wu 2010). Mao and Wang (2018) also found that the 30-60-day ISO was dominant in the intraseasonal variation of the SCS surface temperature. The second is related to the deep convection over the Bay of Bengal (BOB). Liu et al. (2002) showed that the heating released by the vigorous convection over the $\mathrm{BOB}$ triggered the planetary waves propagating in the upper troposphere, which facilitated the cold air intrusion southward to decrease the atmospheric stability over the SCS and induced the SCSSM onset. Zhou et al. (2005) also argued that the determining factor related to the SCSSM onset and the resultant monsoon rainfall might be the off-equatorial ITCZ, in which the cumulus convection would enhance the monsoon trough over the BOB and the SCS.

The third mechanism is the land-sea thermal contrast. Previous studies have been mainly focused on the effect of the heating over the Tibetan Plateau (TP) and surface heat fluxes over the Indochina Peninsula (IP). The sensible heating in spring over the TP affects the BOB summer monsoon onset and then triggers the onset of SCSSM before the Indian summer monsoon onset ( $\mathrm{He}$ et al. 1987; Wu and Zhang 1998). Prior to the SCSSM onset, the IP warms faster than the SCS at $850 \mathrm{hPa}$ (Zhang et al. 2002). The earlier the surface temperature is persistently higher over the IP than the SCS, the earlier the SCSSM establishes (Liu et al. 2010). This mechanism can also be used to explain the onset and intensity of the Asian summer monsoon ( $\mathrm{Li}$ and Yanai 1996; Oh et al. 2018).
All of these three mechanisms show the potential to find predictors on the monthly to seasonal time scales. Zhu and Li (2017) developed two statistical models to predict the SCSSM onset on subseasonal and seasonal time scales by using predictors as the $850-500-\mathrm{hPa}$ air temperature tendency from January to March, sea surface temperature in the tropical Pacific in March, and a dipole sea level pressure pattern over the Southern Hemisphere in January. This study will seek precursory signals by focusing on the most fundamental mechanism underlying monsoon dynamics, that is, thermal contrast. Specifically, in addition to the springtime TP heating, is there any other precursory thermal signal on the monthly to seasonal time scales for the SCSSM onset? Furthermore, we would like to understand how long the thermal-contrast signal can be observed before the SCSSM onset and whether it can be easily observed and/or measured.

The objectives of this study are 1) to identify a precursory thermal-contrast signal that is easy to measure and 2) to quantitatively evaluate the main processes contributing to the variation in this signal. Data and method are described in section 2. The precursory thermal-contrast signal is examined in section 3. Sections 4 and 5 show the process-level attribution analyses and the mechanism of the dominant process, respectively. The results are summarized in section 6 .

\section{Data and method}

We use the atmospheric variables from the European Centre for Medium-Range Weather Forecasts interim reanalysis (ERA-Interim; Dee et al. 2011), which covers the period from 1979 to the present. Variables include monthly mean solar insolation at the top of the atmosphere (TOA), air and surface temperatures, specific humidity, cloud amount, cloud liquid and cloud ice water content, surface albedo, ozone mixing ratio, soil moisture, and precipitation. All of the variables have a horizontal resolution of $1^{\circ}$ longitude $\times 1^{\circ}$ latitude, with atmospheric variables having 37 pressure levels from 1000 to $1 \mathrm{hPa}$. We also use the monthly mean precipitation from the Climate Prediction Center of the National Oceanic and Atmospheric Administration, which has a horizontal resolution of $2.5^{\circ}$ longitude $\times 2.5^{\circ}$ latitude. In addition, the monthly mean oceanic temperature is provided by the National Centers for Environmental Prediction Global Ocean Data Assimilation System, which has a horizontal resolution of $2.5^{\circ}$ longitude $\times 2.5^{\circ}$ latitude.

The major analysis tool is the Climate FeedbackResponse Analysis Method (CFRAM) (Cai and $\mathrm{Lu}$ 2009; Lu and Cai 2009), which is under the framework of 
the total energy balance within an atmosphere-surface column. Here, we take the climatological monthly mean temperature in March during 1979-2016 as the energybalanced basic state, and the monthly mean temperature in March of each year from 1979 to 2016 as the energybalanced anomalous state. We consider the total energybalance equation separately for both states, take the difference $\Delta$, and then obtain

$$
\Delta \frac{\partial E}{\partial t}=\Delta S-\Delta R+\Delta Q^{\text {nonradiative }} .
$$

On the left-hand side of Eq. (1), $\Delta \partial E / \partial t$ represent the changes in the rate of energy storage. On the right-hand side of Eq. (2), $S$ and $R$ denote the vertical profile of the net shortwave radiation convergent and net longwave radiation divergent within each layer, and $\Delta Q^{\text {nonradiative }}$ represents the energy convergent at each layer by the nonradiative processes. Above the surface, the nonradiative processes include atmospheric turbulent, convective, and advective motions, while at the surface they indicate the surface heat fluxes and land heat storage if the land is covered by large runoff, as well as the oceanic dynamics and heat storage in the ocean mixed layer if the surface is over oceans. All terms in Eq. (1) are in units of watts per square meter.

As in Deng et al. (2013) and Li et al. (2018), based on the linear assumption, $\Delta S$ and $\Delta R$ are expressed as the sum of convergent and divergent partial radiative energy flux perturbations due to all individual radiative processes in the atmosphere-surface column:

$$
\begin{aligned}
& \Delta S \approx \Delta S^{\text {solar }}+\Delta S^{\mathrm{wv}}+\Delta S^{\text {cloud }}+\Delta S^{\alpha}+\Delta S^{\mathrm{CO}_{2}}+\Delta S^{\mathrm{O}_{3}}, \\
& \Delta R \approx \Delta R^{\mathrm{wv}}+\Delta R^{\text {cloud }}+\Delta R^{\mathrm{CO}_{2}}+\Delta R^{\mathrm{O}_{3}}+\Delta T \frac{\partial R}{\partial T},
\end{aligned}
$$

where superscripts solar, wv, cloud, $\alpha, \mathrm{CO}_{2}$, and $\mathrm{O}_{3}$ represent solar insolation at the TOA, water vapor, cloud, surface albedo, carbon dioxide, and ozone, respectively; $\partial R / \partial t$ is the Planck feedback matrix.

Substituting Eq. (2) into Eq. (1), we obtain

$$
\begin{aligned}
\Delta T= & \left(\frac{\partial R}{\partial T}\right)^{-1}\left[\Delta S^{\text {solar }}+\Delta(S-R)^{\mathrm{wv}}+\Delta(S-R)^{\text {cloud }}\right. \\
& +\Delta(S-R)^{\mathrm{CO}_{2}}+\Delta(S-R)^{\mathrm{O}_{3}}+\Delta S^{\alpha} \\
& \left.+\Delta Q^{\mathrm{ATD}}+\Delta Q^{\text {surf }}\right] .
\end{aligned}
$$

The atmosphere part of $\Delta Q^{\text {nonradiative }}$ in Eq. (1) is represented by $\Delta Q^{\mathrm{ATD}}$ here, which is zero at the surface layer, and $\Delta Q^{\mathrm{ATD}}=-\Delta(S-R)_{\mathrm{atmos}}$ in the atmosphere layers, representing the vertical profile of the energy perturbation associated with atmospheric motions) and heat storage anomalies (expected to be very small) (ATM). The surface part of $\Delta Q^{\text {nonradiative }}$ in Eq. (1) is replaced by $\Delta Q^{\text {surf }}$ here, which is zero in the atmosphere layers, and $\Delta Q^{\text {surf }}=-\Delta(S-R)_{\text {surf }}$ at the surface layer, representing the energy perturbation at the surface due to two parts as 1) the changes in surface turbulent sensible $\left(\Delta Q^{\text {sshf }}\right)$ and latent $\left(\Delta Q^{\text {slhf }}\right)$ heat flux anomalies and 2) the changes in the rate of land-ocean heat storage and the oceanic dynamic circulation. Thus, the second part, the oceanic dynamics and land-ocean heat storage term (Ocn), is estimated as the residual of the surface energy-balance equation, $\Delta Q^{\mathrm{Ocn}}=-\Delta(S-R)_{\text {surf }}-$ $\left(\Delta Q^{\text {sshf }}+\Delta Q^{\text {shf }}\right)$.

Based on Eq. (3), the monthly temperature anomalies in March (with respect to the March climatology) at the surface layer over the South China Sea summer monsoon region as the sum of the partial temperature anomalies associated with anomalies in the carbon dioxide concentration, ozone mixing ratio, solar insolation, water vapor, cloud, surface albedo, ATM, and Ocn. We subtract the temperature anomalies over land from those over ocean for observed and partial temperatures separately to get process-level decomposition of the thermal contrast.

To quantify the relative contribution of each process $i$ to the variations of the thermal-contrast signal from both its variability and amplitude, as in Li et al. (2018), we calculate the temporal pattern-amplitude projection $\left(\mathrm{TPAP}_{i}\right)$ coefficients as follows:

$$
\operatorname{TPAP}_{i}=\frac{\sum_{j=1}^{38}\left(D T_{i j} D T_{j}\right)}{\sum_{j=1}^{38} D T_{j}^{2}},
$$

where $i$ refers to the feedback process, and $j$ refers to years (1979-2016). Moreover, $D T_{j}$ represents the observed thermal-contrast signal in March of the $j$ th year, and $D T_{i j}$ stands for the observed thermal contrast related to process $i$ in March of the $j$ th year.

\section{Precursory thermal-contrast signal of the SCSSM onset}

The SCSSM onset is characterized by an intensification of the tropical southwesterlies, which can be measured by the 850 -hPa zonal winds averaged over $5^{\circ}-15^{\circ} \mathrm{N}, 110^{\circ}-120^{\circ} \mathrm{E}\left(U_{\mathrm{SCS}}\right.$; Wang et al. 2004$)$. The onset date of SCSSM is defined by Wang et al. (2004) as the first pentad after 25 April that satisfies the following two 


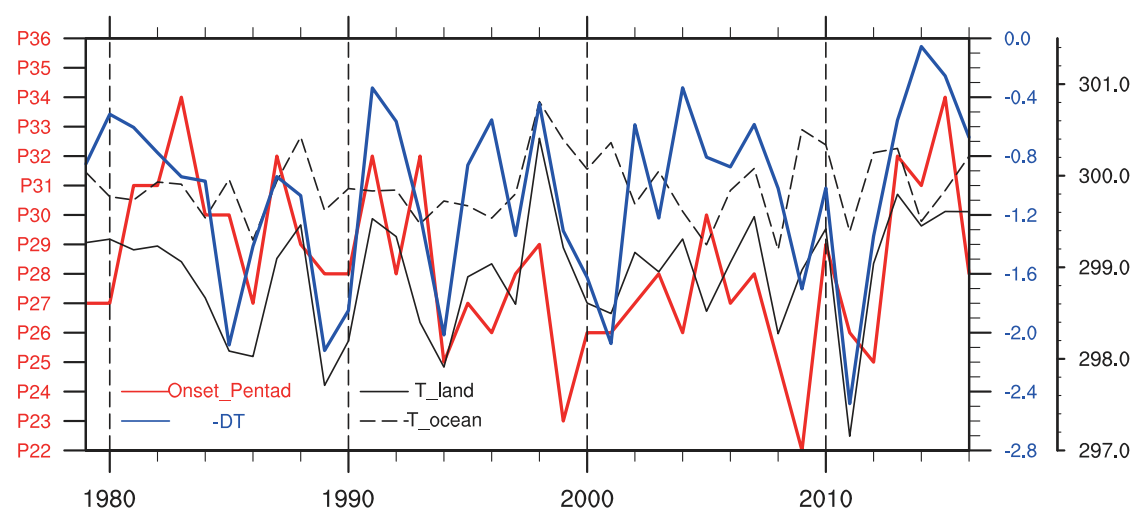

FIG. 1. Time series of the onset pentad of the SCSSM (red) based on the definition in Wang et al. (2004), land-sea thermal contrast $-D T\left(T_{\text {land }}-T_{\text {ocean }}\right)$ in March over $5^{\circ}-20^{\circ} \mathrm{N}, 100^{\circ}-$ $120^{\circ} \mathrm{E}$ (blue), and areal mean $T_{\text {land }}$ (solid black) and $T_{\text {ocean }}$ (dashed black) over $5^{\circ}-20^{\circ} \mathrm{N}, 100^{\circ}-$ $120^{\circ}$ E during 1979-2016.

criteria: 1) in the onset pentad, $U_{\mathrm{SCS}}>0$ and 2) in the subsequent four pentads (including the onset pentad), $U_{\text {SCS }}$ must be positive in at least three pentads and the accumulative four-pentad mean $U_{\mathrm{SCS}}>1 \mathrm{~m} \mathrm{~s}^{-1}$. Following these criteria, we derive the SCSSM onset pentad as the red curve shows in Fig. 1. While the climatological onset time of SCSSM is around mid-May, it exhibits strong interannual and interdecadal variations. Robust interdecadal changes occur in 1993-94 and 2002-03, where the averaged onset date is around pentad 28 before 1993 and around pentad 26 during 1994-2002.

The robust reversal and enhanced low-level winds associated with SCSSM onset are coherently related to the low-level thermal condition (Zhang et al. 2002). Climatologically, in March (Fig. 2a), the near-surface temperature features strong meridional gradient over the SCS as $T_{2 \mathrm{~m}}$ decreases from 27 to $17 \mathrm{~K}$ from the southern to the northern SCS. Over the northern BOB it is as high as $27 \mathrm{~K}$, much warmer than the SCS for the same latitude. Anticyclonic flow prevails over the SCS and two rainfall centers are over southern China and the Maritime Continent. The first center may be induced by the frontal system involving the interaction between the wet and warm southwesterlies from the tropical region and the dry and cold northerlies from the midlatitude region. The other center is associated with deep convection resulted from the convergence of the prevailing easterly winds near the equator. From March to April, both rainfall centers expand along with the eastward-retreated anticyclonic flow (Fig. 2b). As the anticyclone retreats eastward and strong southwesterlies prevail over the Indochina Peninsula and the northern SCS, an abrupt increase in rainfall occurs over the SCS in May, indicating onset of the SCSSM (Fig. 2c). The enhanced rainfall over the SCS in May results from the eastward propagation of strong precipitation from the $\mathrm{BOB}$ and the northward propagation of vigorous rainfall from the Maritime Continent. Accompanied with the rainfall evolution, near-surface temperature is characterized by pronounced variations. The "cold tongue" of SST along the eastern coastline of the Indochina Peninsula rapidly disappears from March to April, and SST warms rapidly in AprilMay, especially from the eastern BOB to the SCS and from the southern SCS to the northern SCS. Meanwhile, the near-surface temperature over land warms up at a relatively slower rate than over oceans. Deep convection is well collocated over warm SST, and local warmer SST triggers the deep convection over the eastern BOB in April and over the SCS in May. Thus, the variation of the SCSSM onset is coherently correlated with the variations of near-surface temperature over the SCS and its adjacent area.

When the SCSSM onset time advances, more rainfall occurs over the SCS in May, accompanied by anomalously cyclonic circulation at the low levels and anomalous cooling in the SCS and the Indochina Peninsula (Fig. 3c). The precursory signals can be seen in March (Fig. 3a) and April (Fig. 3b), where the land temperature tends to be cooler and the ocean temperature tends to be warmer. Since the climatological SST over the SCS is warmer than the Indochina Peninsula, such an anomalous temperature pattern represents a stronger land-sea thermal contrast in March and April. Such a thermal pattern at the surface facilitates anomalously cyclonic circulations in the vicinity of SCS, leading to more rainfall over the southern SCS. Because more precipitation over the warmer ocean indicates that the warmer ocean forces circulation changes, this thermal pattern triggers deep convection in March and April. 
(a) Mar

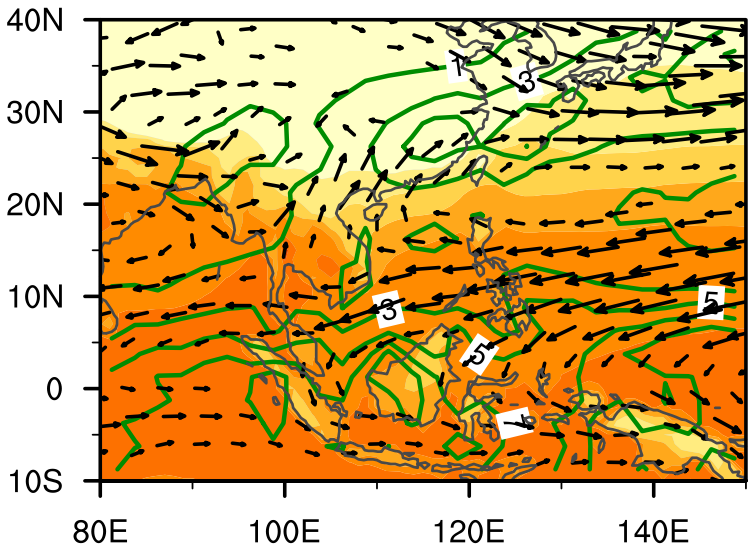

(b) Apr

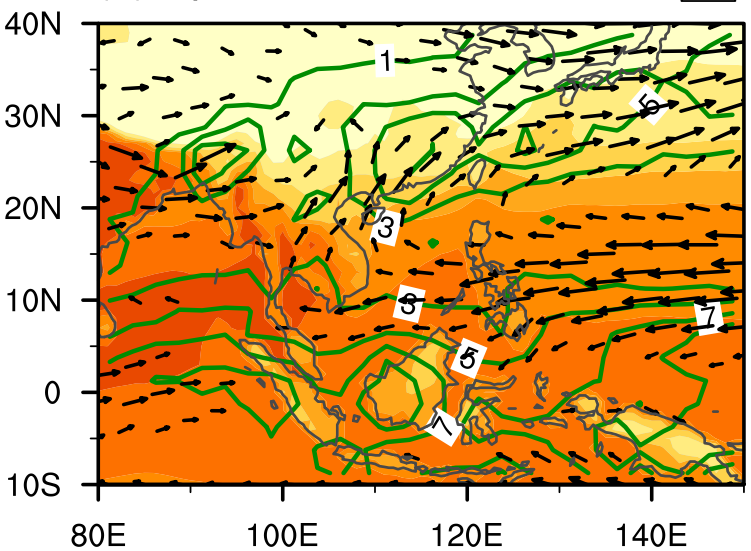

(c) May

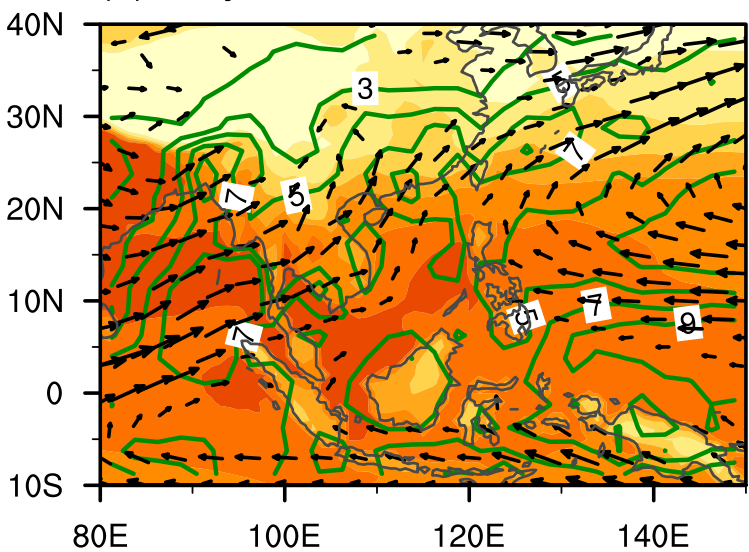

\section{$\begin{array}{llllll}290 & 295 & 298 & 300 & 302 & 303\end{array}$}

FIG. 2. Climatology of monthly mean surface temperature $\left(T_{s}\right.$, $T_{2 \mathrm{~m}}$ over the land, and SST over the ocean; shading; K), precipitation (contours; $\mathrm{mm} \mathrm{day}^{-1}$ ), and $850-\mathrm{hPa}$ winds (vectors; $\mathrm{m} \mathrm{s}^{-1}$ ) in (a) March, (b) April, and (c) May during 1979-2016. (a) Mar

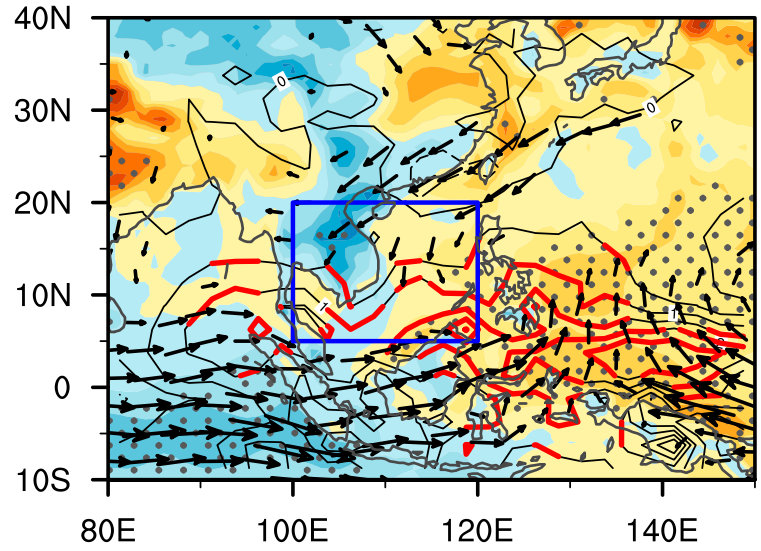

(b) Apr

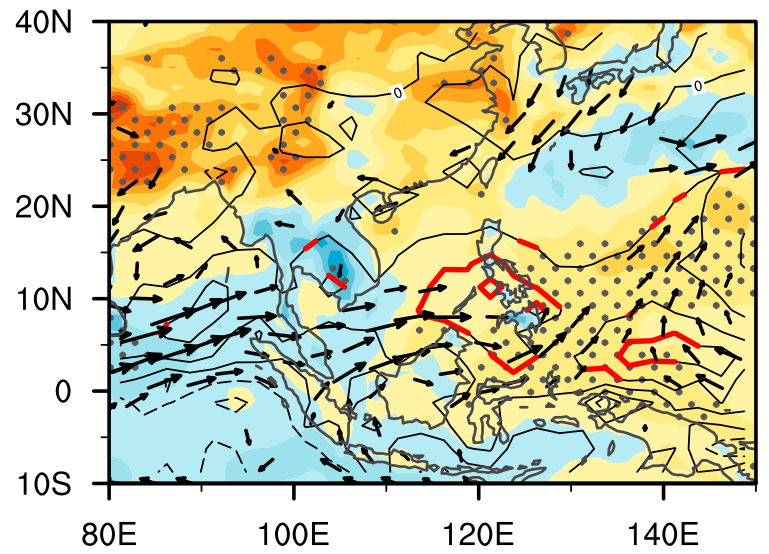

(c) May

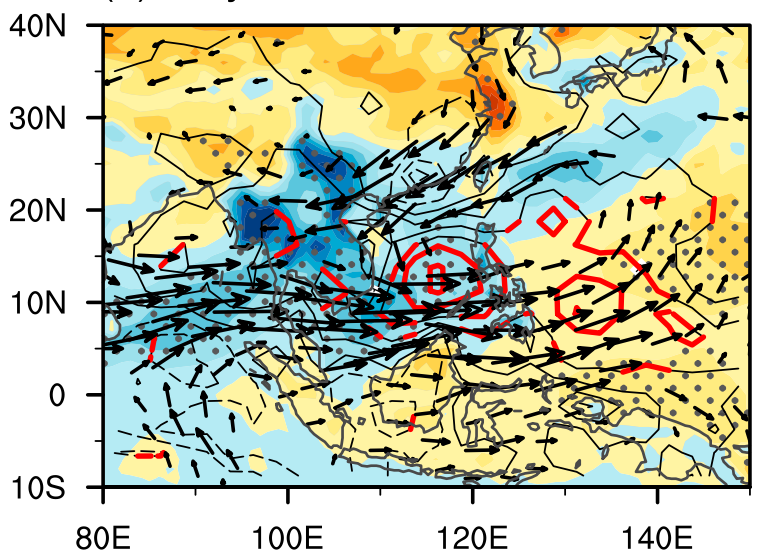

\section{$\begin{array}{lllllll}-0.6 & -0.4 & -0.2 & 0 & 0.2 & 0.4 & 0.6\end{array}$}

FIG. 3. Regression coefficients of $T_{s}$ (shading; K), 850-hPa winds (vectors; $\mathrm{m} \mathrm{s}^{-1}$ ), and precipitation (contours; $\mathrm{mm} \mathrm{day}^{-1}$ ) in (a) March, (b) April, and (c) May against the SCSSM onset pentad index during 1979-2016. Stippled areas, thicken red contours, and all vectors are significant at the $95 \%$ confidence level. The blue box in (a) indicates the $D T$-defined domain as $5^{\circ}-20^{\circ} \mathrm{N}, 100^{\circ}-120^{\circ} \mathrm{E}$. 
(a) Mar

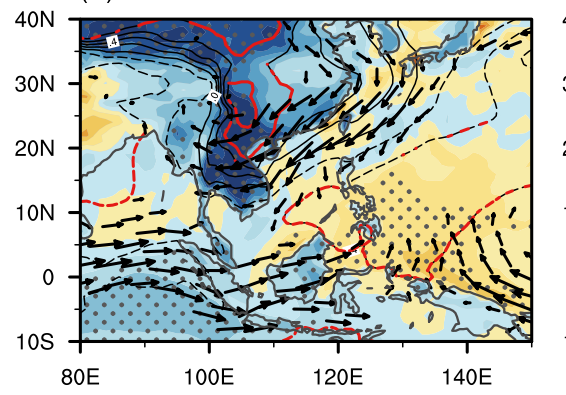

(b) Apr

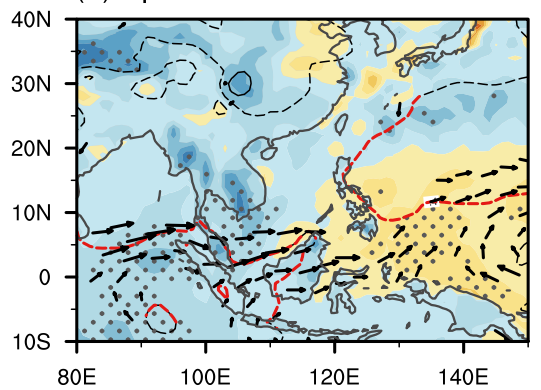

(c) May

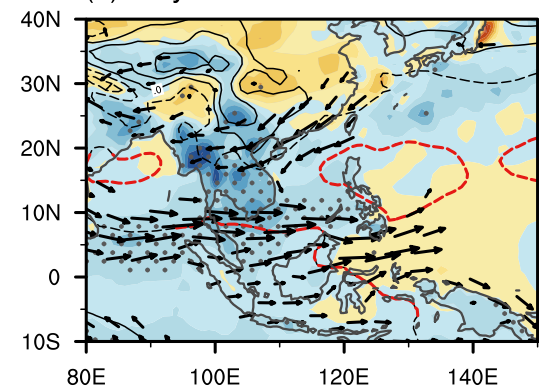

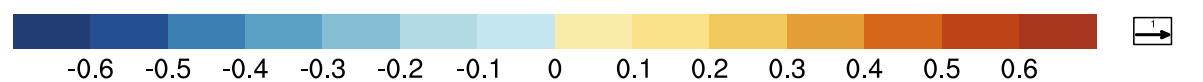

(d) Mar

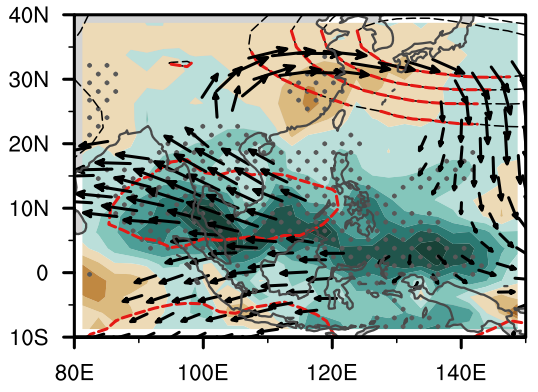

(e) Apr

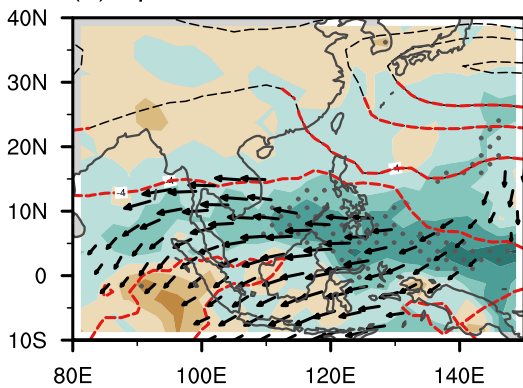

(f) May

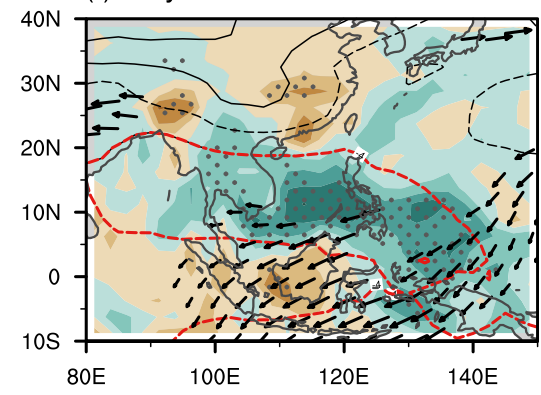

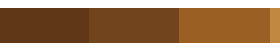

$-2 \quad-1.6 \quad-1$.

$1.2-0.8$
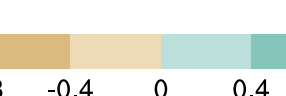

1.21 .6

FIG. 4. Regression coefficients of (a)-(c) $T_{s}$ (shading; K), 850-hPa winds (vectors; $\mathrm{m} \mathrm{s}^{-1}$ ), and sea level pressure (SLP; contours; hPa) and (d)-(f) precipitation (shading; $\mathrm{mm} \mathrm{day}^{-1}$ ), 200-hPa winds (vectors; $\mathrm{m} \mathrm{s}^{-1}$ ), and 500-hPa geopotential height (contours; gpm) in (left) March, (middle) April, and (right) May against the index DT during 1979-2016. Stippled areas, thicken red contours, and all vectors are significant at the $95 \%$ confidence level.

The above-discussed land-sea thermal-contrast signal seems to be a potential predictor of the SCSSM onset time. We calculate the land-sea thermal contrast as 2-m temperature over land $T_{\text {land }}$ minus SST $T_{\text {ocean }}$, that is, $T_{\text {land }}-T_{\text {ocean }}$, over $5^{\circ}-20^{\circ} \mathrm{N}, 100^{\circ}-120^{\circ} \mathrm{E}$ (see the blue box in Fig. 3a). It is seen that the thermal contrast in March is more significantly correlated with the SCSSM onset time $(r=0.42)$ than that in April $(r=0.28)$ and in May $(r=0.30)$. Thus, we define this land-sea thermal-contrast signal in March as an index $-D T$, explicitly $-D T=T_{\text {land }}-T_{\text {ocean }}$ over $5^{\circ}-20^{\circ} \mathrm{N}, 100^{\circ}-120^{\circ} \mathrm{E}$ (see the blue curve in Fig. 1). Also shown in Fig. 1, the SST (the dashed black curve) is warmer than the adjacent land temperature (the solid black curve) in March, and the climatological $-D T$ is about $-1.5 \mathrm{~K}$. To be more easily taken, $D T$ is used as the indicator in the following analyses. The larger $D T$, the greater the land-sea thermal contrast; and the variation of $D T$ is more determined by that of $T_{\text {land }}(r=0.818)$ than that of $T_{\text {ocean }}$ in this region $(r=-0.019)$.
When the land-sea thermal contrast is larger in March (Fig. 4a) with a cooler land and a warmer ocean, the anomalous circulation of strong northwesterlies along the coastline and westerlies near the equator form a cyclonic circulation at low levels, while significant divergent winds are collocated at the higher levels (Fig. 4d). This anomalous structure favors enhanced precipitation over the SCS in March. Such an anomalous circulation persists from April to May to advance the SCSSM onset, although it becomes weaker in April. From the relationship with atmospheric circulation, the land-sea thermal contrast in March can exert a substantial impact on the variation of SCSSM onset and can be taken as a precursory thermal signal.

$D T$ is an easily measured thermal-contrast signal. As this thermal signal is derived from near-surface temperature, which is affected by various processes, it is of substantial interest to investigate which processes control or modulate the variation of $D T$ and understand the underlying mechanisms for the formation of this precursory signal. 


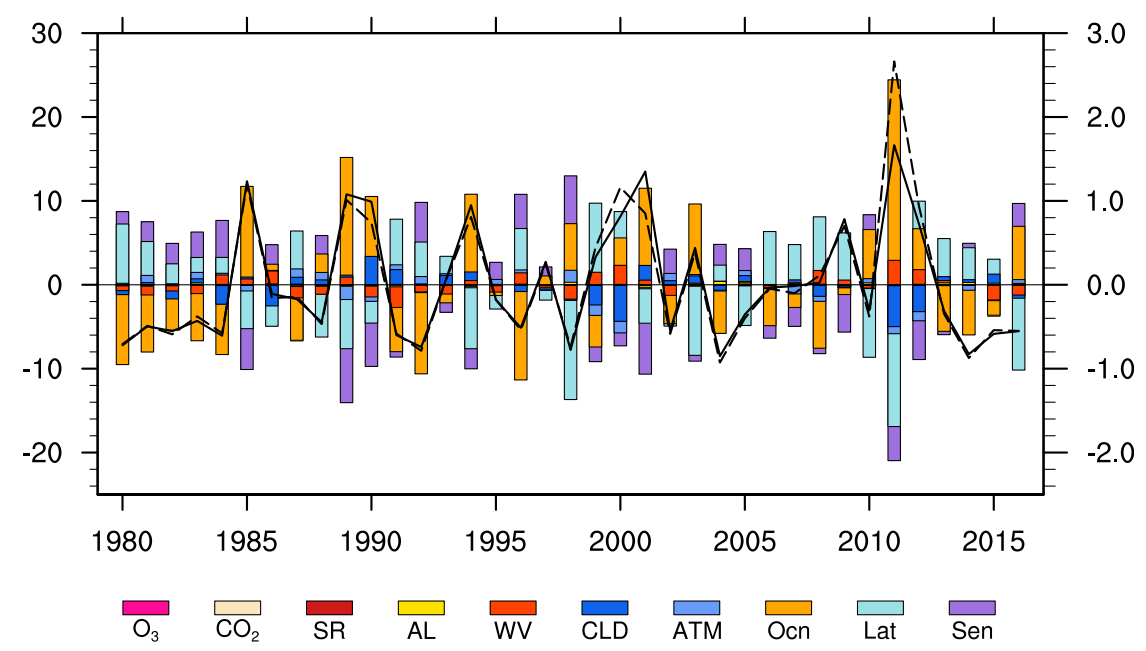

FIG. 5. Partial DT (bars; corresponding to the left $y$ axis) due to changes in each process (listed as annotations) in March between each year and the climatology mean during 19802016. The sum of the partial $D T$ of all individual processes is shown as the dashed black line, and the observed is indicated by the solid black line (corresponding to the right $y$ axis). The annotations from left to right refer to ozone, carbon dioxide, solar radiation at the TOA, surface albedo, water vapor, cloud, atmospheric motions, oceanic dynamics and ocean-land heat storage, surface latent heat flux, and surface sensible heat flux.

\section{Process-based attribution of the interannual variation of $D T$}

To explore the main contributors, the dynamical analysis method CFRAM is applied to quantify the contributions of all the radiative and nonradiative processes in the ocean-atmosphere system to the variation of $D T$. As mentioned in section 2, we take the monthly mean DT in March during 1979-2016 as the base state. The solid black curve in Fig. 5 shows the variation of anomalous $D T$ compared with the climatology. The dashed curve depicts the same variable as the solid line, but for the result from CFRAM analysis. Except for the relatively large bias in 2011, the result obtained from the CFRAM nicely replicate the observation.

Partial $D T$ anomalies due to annual anomalies in each process also exhibit strong interannual variability (bars in Fig. 5). In terms of magnitude, Ocn and surface latent and sensible heat fluxes are the first-order contributors, while cloud, water vapor, and atmospheric dynamics are the second-order contributors. To quantify the overall contributions to DT during 1979-2016, the TPAP (see section 2) is employed to measure both the magnitude and the temporal pattern of each process. As shown in Fig. 6a, the variation of Ocn is the largest positive contributor to $D T$, followed by water vapor, while surface heat fluxes are the largest negative contributor, followed by the ATM and cloud.

As mentioned before, since the variation of $D T$ is largely dominated by the variation of $T_{\text {land }}$ other than that of $T_{\text {ocean }}$, it is of interest to analyze the variations of $T_{\text {land }}$ and $T_{\text {ocean }}$ separately. The key positive contributor is still Ocn, to both $T_{\text {land }}$ and $T_{\text {ocean }}$, while the other processes vary apparently. For instance, the variation of cloud turns out to be the second largest positive contributor, especially for $T_{\text {land }}$, while the variation of water vapor even switches to a negative factor. The surface heat fluxes still negatively contribute to the variation of $T_{\text {land }}$, but positively modulate the variation of $T_{\text {ocean }}$, both with relatively weaker magnitudes compared with those to the variation of $D T$. Moreover, the contributions of cloud (positive) and the atmospheric dynamics (negative) become more relevant in the individual variations of $T_{\text {land }}$ and $T_{\text {ocean }}$. Overall, compared with the contributors to $T_{\text {ocean }}$, the main contributors to the variation of $T_{\text {land }}$ more highly resemble those of the variation of $D T$.

\section{The dominant contributing processes}

The quantitative evaluation via the CFRAM makes it easy to reveal the main processes contributing to the variation of $D T$. How these dominant processes work is further discussed in this section. When the land-sea thermal contrast is larger in March, more water vapor converges over the southern SCS and the Indochina Peninsula with much more over oceans than over land (Fig. 7a). Since water vapor radiatively warms the surface via its longwave effect, the warming caused by the 
(a) DT

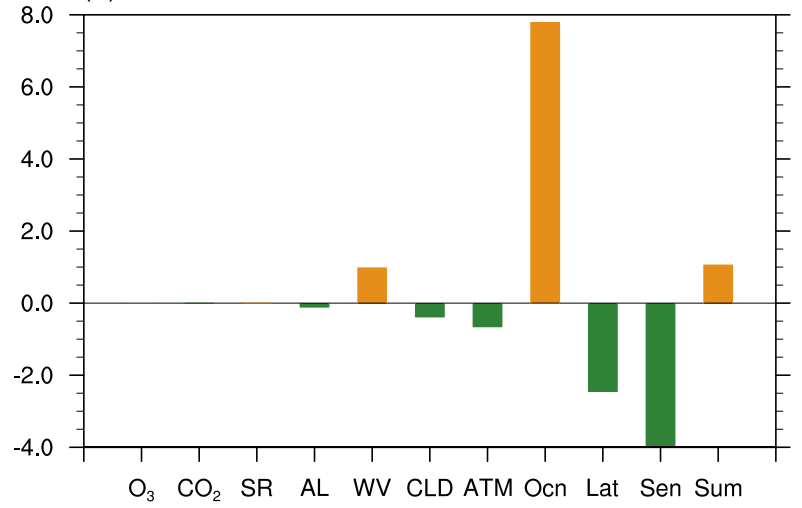

(b) Ts_Land

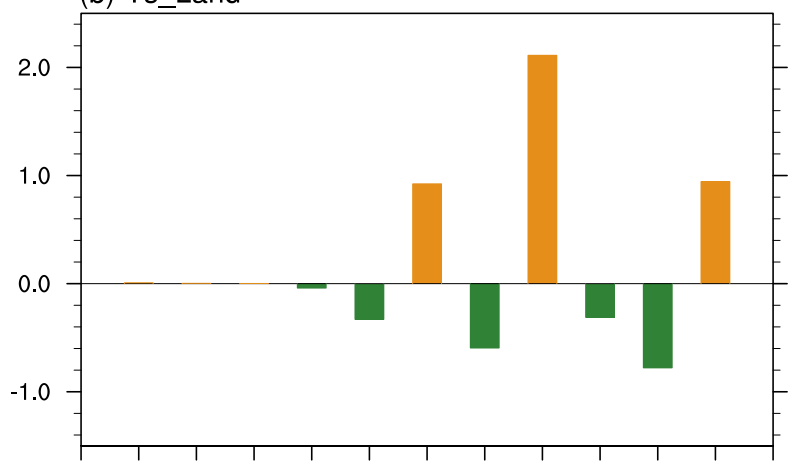

$\mathrm{O}_{3} \quad \mathrm{CO}_{2} \quad \mathrm{SR} \quad \mathrm{AL} \quad \mathrm{WV}$ CLD ATM Ocn Lat Sen Sum

(c) SST

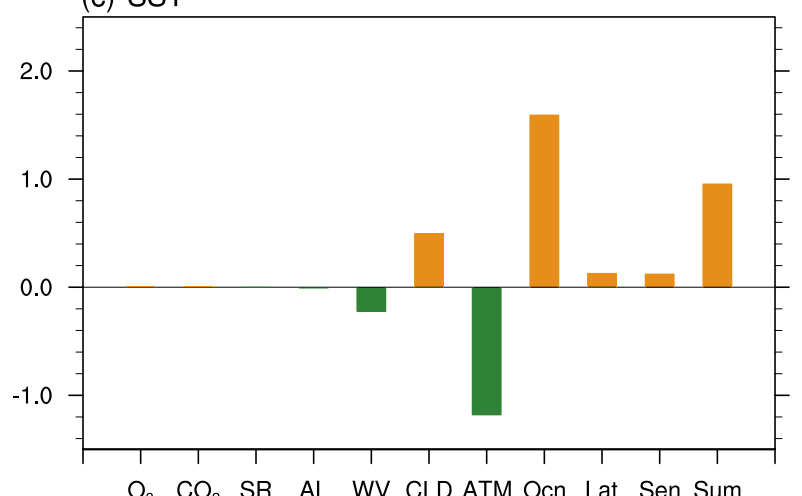

FIG. 6. Temporal pattern-amplitude projection (TPAP) coefficients of each process to the variation of (a) $D T$, (b) areal mean $T_{\text {land }}$, and (c) areal mean $T_{\text {ocean }}$ over $5^{\circ}-20^{\circ} \mathrm{N}, 100^{\circ}-120^{\circ} \mathrm{E}$ in March.

variation of water vapor over the southern SCS is larger than that over the land. This effect amplifies the climatological pattern of land-sea thermal contrast, and therefore advances the SCSSM onset. Variations of water vapor thus tend to contribute positively to the variation of $D T$. The spatial distribution of cloud resembles that of the water vapor (Fig. 7b). Since cloud cools the surface in the tropical region via preventing the incidence of shortwave radiation, more clouds over

\section{(a) WVFlux\&Div} $\mathrm{kg}^{*} \mathrm{~m}^{*} \mathrm{~Pa} /\left(\mathrm{kg}^{*} \mathrm{~s}\right)$

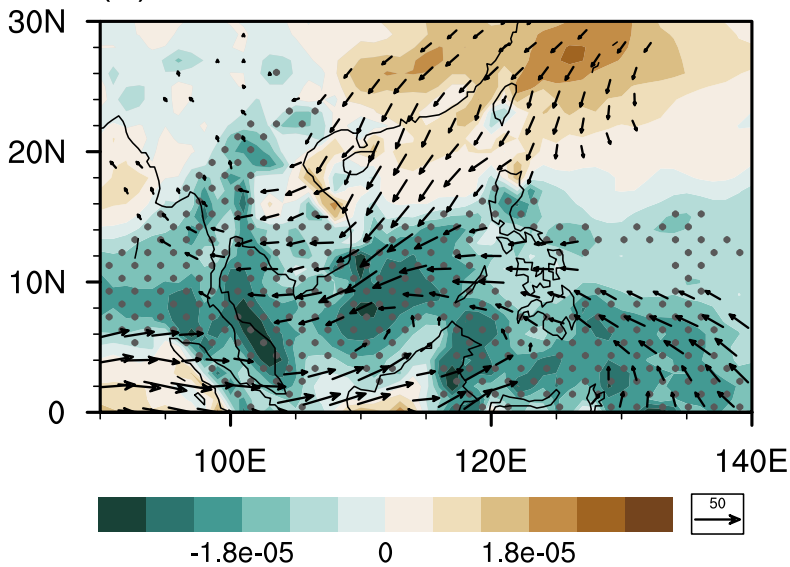

(b) Cloud Cover

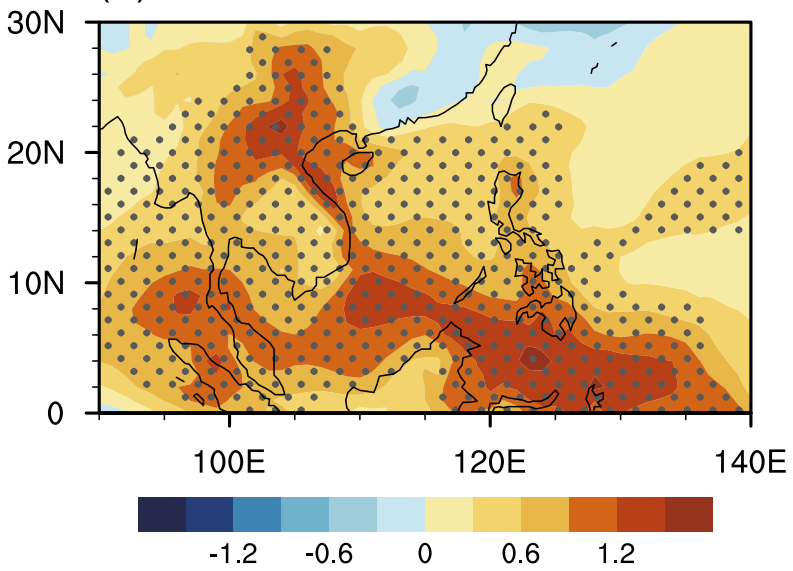

(c) Surf. Heat Flux

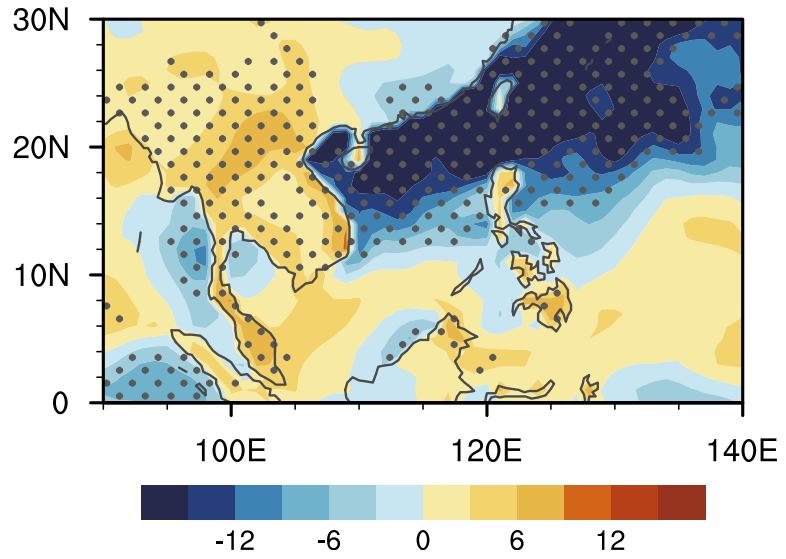

FIG. 7. Regression coefficients of (a) 300-1000-hPa integral water vapor flux [vectors; $\mathrm{kg} \mathrm{m} \mathrm{Pa}\left(\mathrm{kg} \mathrm{s}^{-1}\right.$ ] and its divergence (shading), (b) 300-1000-hPa cloud cover, and (c) surface heat fluxes $\left(\mathrm{W} \mathrm{m}^{-2}\right)$ in March against DT in March during 1979-2016. Stippled areas and all vectors are significant at the $95 \%$ confidence level. 
(a) SST

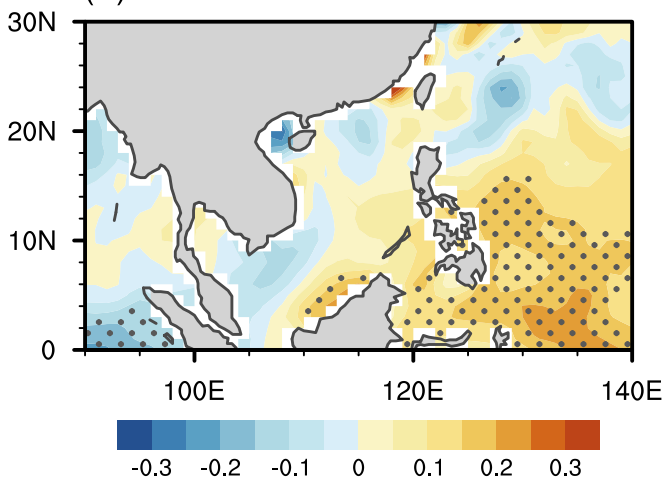

(b) OHS Rate

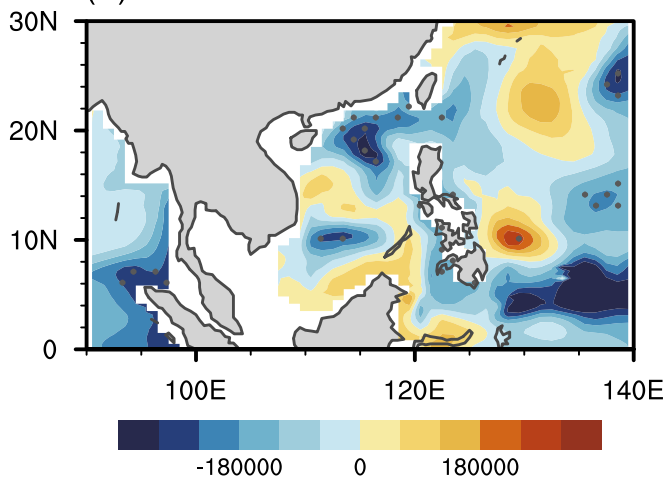

(c) Ts

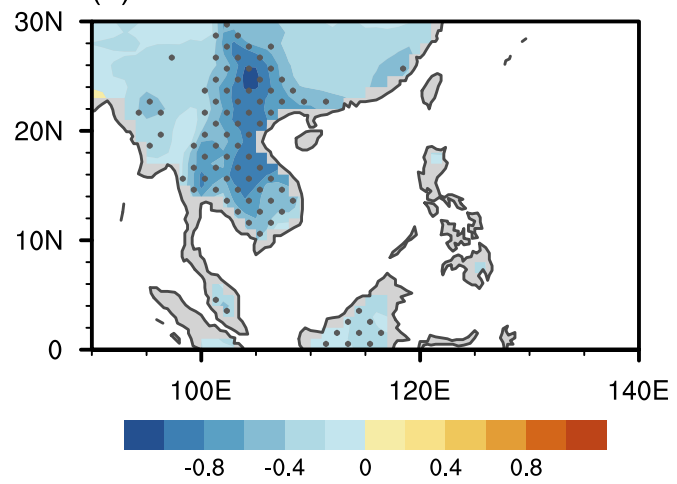

(d) Soil Moisture

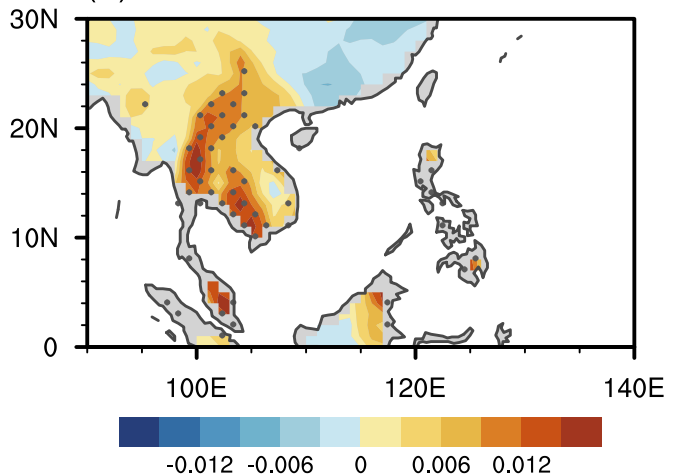

FIG. 8. As in Fig. 7, but for (a) SST, (b) 0-205-m oceanic heat storage rate, (c) $T_{2 \mathrm{~m}}$, and (d) 0-28-cm soil moisture $\left(\mathrm{m}^{3} \mathrm{~m}^{-3}\right)$ in March. Stippled areas are significant at the $95 \%$ confidence level.

oceans than over the land would weaken the original land-sea thermal contrast to delay SCSSM onset. Therefore, the variations of clouds negatively contribute to the variation of $D T$.

As the largest negative contributor, the variation of surface heat fluxes, shows an apparent land-sea contrast with enhanced upward fluxes over oceans and downward fluxes over the land (Fig. 7c). Its impact on surface temperature weakens the land-sea thermal contrast due to its cooling effect on SST and warming effect on land temperature. Thus, the variation of surface heat fluxes contributes negatively to the variation of $D T$. Moreover, the area of robustly negative correlations over the oceans extends from the southern SCS to the northwest Pacific, which means that the thermal state of the Pacific also exerts an effect on the variation of $D T$.

The largest positive contributor Ocn includes two parts: 1 ) the oceanic dynamics and heat storage rate and 2 ) the land heat storage rate. For the ocean part, a decrease in the ocean heat storage rate (Fig. 8b), especially over the northern and central SCS, facilitates the warming of SST (Fig. 8a). Since the SST is determined by not only the ocean circulation (heat content and dynamics) but also surface wind and heat fluxes, the SST pattern does not necessarily collocate well with the pattern of oceanic heat storage rate, but still shows an overall weak warming in the analysis domain. As shown in Figs. $8 \mathrm{c}$ and $8 \mathrm{~d}$, the spatial pattern of the negative correlation with $T_{2 \mathrm{~m}}$ well resembles that of the positive correlation with the $0-28-\mathrm{cm}$ soil moisture. It suggests that the increase in soil moisture favors the cooling of land surface. Thus, the cooling over land due to increases in soil moisture and the warming over oceans due to decreases in oceanic heat storage rate collectively contribute to a larger land-sea thermal contrast to advance SCSSM onset.

\section{Discussion and conclusions}

\section{a. Discussion}

The variation of $D T$ can be regarded as a precursory thermal-contrast indicator for SCSSM onset, explained by the dominant contributing processes derived from the CFRAM analysis. Its strong relationship with soil moisture and oceanic circulation shows it as a potential 
(a) DT

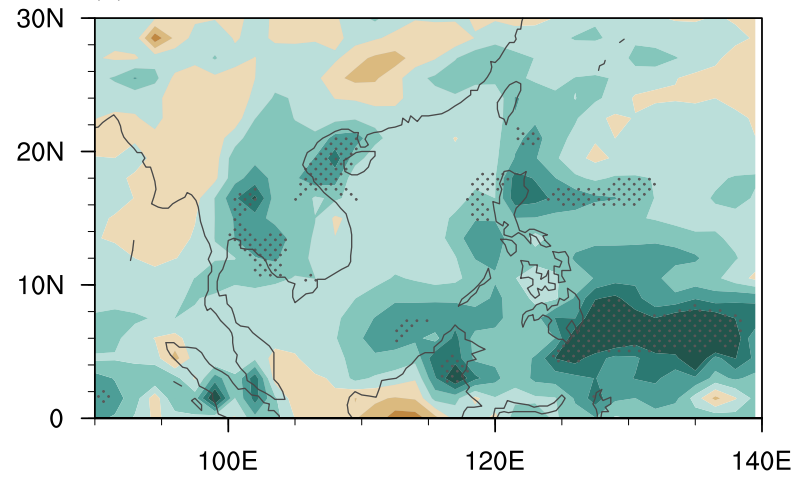

(b) Soil Moisture

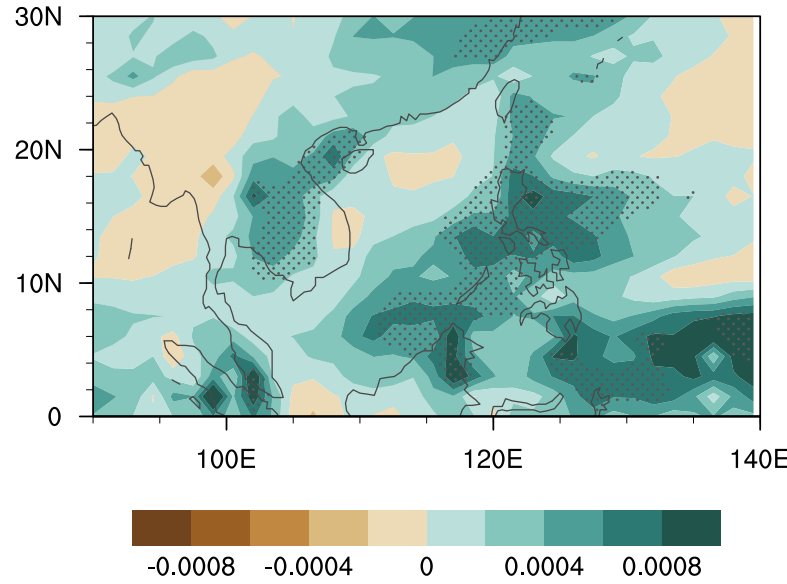

FIG. 9. Regression coefficients of daily mean precipitation in during 20-28 (or 20-29) Feb against (a) DT in March and (b) 0-28-cm soil moisture over land of $5^{\circ}-20^{\circ} \mathrm{N}, 100^{\circ}-120^{\circ} \mathrm{E}$ in March. Stippled areas are significant at the $95 \%$ confidence level.

predictor for the SCSSM onset, since the ground wetness over land and the ocean temperature have a longer memory than the typical atmospheric variables (Yang and Lau 1998).

The soil moisture over the Indochina Peninsula exhibits low-frequency variability (around 33 days) and is capable of retaining anomalous atmospheric signals in previous months. As Fig. 9a shows, $D T$ is positively related with the daily mean precipitation in late February over the Indochina Peninsula. Thus, the precipitation amount in late February can be considered as a precursory signal for the $D T$ anomalies in March.

More robust preceding signals of the variations of $D T$ lie in the variability of tropical SST. From the lead-lag regression, $D T$ is coherently related with the SST in the tropical and southern Indian Ocean and the tropical Pacific (Fig. 10). When the land-sea thermal contrast is larger in March, a robust La Niña-like pattern is persistent from January to April, and then weakens with time. Warmer SST over the tropical western Pacific benefits larger land-sea thermal contrast in March over the analysis domain. This relationship is consistent with the result by previous studies as late SCSSM onset often follows an El Niño event in the preceding winter and spring, while early onsets are associated with La Niña events, noting that the relationship is not symmetric (e.g., Xie et al. 1998; He et al. 2017).

\section{b. Conclusions}

Land-sea thermal contrast is one of the fundamental mechanisms modulating the interannual variations of SCSSM onset. Based upon the well-explained underlying physical process of the thermal contrast, this study is aimed to explore a spring precursory, easily measured thermal-contrast signal of the SCSSM onset. The SCSSM onset exhibits strong interannual variability and is correlated coherently with the land-sea thermal contrast at the surface in March $\left(D T=T_{\text {ocean }}-T_{\text {land }}\right)$ over $5^{\circ}-20^{\circ} \mathrm{N}, 100^{\circ}-120^{\circ} \mathrm{E}$. The anomalous circulation associated with $D T$ features that when the land-sea thermal contrast is larger, a low-level cyclonic circulation is present over the warmer SCS and western tropical Pacific, and divergent winds is collocated at the upper levels, resulting in deep convection over the SCS in March. This rainfall-facilitating circulation persists from March to May to advance the SCSSM onset time.

To further understand the variation of $D T$, the CFRAM analysis method is applied to quantify the contributions of all the radiative and nonradiative processes to the annual $D T$ anomalies. The largest positive (strengthening the land-sea thermal contrast) contributing process is the oceanic dynamics and ocean-land heat storage, followed by water vapor, while the largest negative (weakening the land-sea thermal contrast) one is surface heat fluxes, followed by atmospheric dynamics and clouds. When $D T$ is larger, water vapor converges more over the southern SCS than over the Indochina Peninsula, which amplifies the climatological "cooler land-warmer ocean" thermal contrast due to more warming over land than over the oceans via the greenhouse effect of water vapor. Similar to the anomalous distribution of water vapor, cloud amount increases more over the southern SCS than over the Indochina Peninsula when $D T$ is larger. This anomalous pattern weakens the climatological land-sea thermal contrast due to more cooling over the oceans than over land via the impact of the shortwave effect of clouds. For the surface heat fluxes, when the thermal contrast is larger, more upward heat fluxes over the SCS and more downward fluxes over the Indochina Peninsula weaken the land-sea thermal contrast. For the largest positive contributor Ocn, the robust cooling over land due to enhanced ground wetness and the warming over the 
(a) Dec

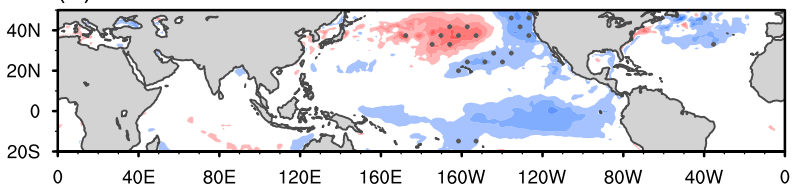

(c) Feb

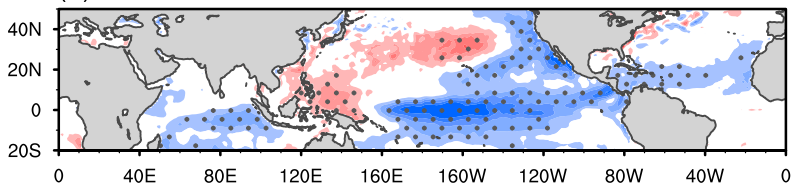

(e) Apr

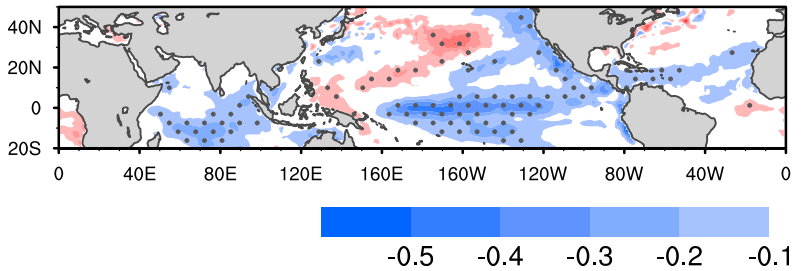

(b) Jan

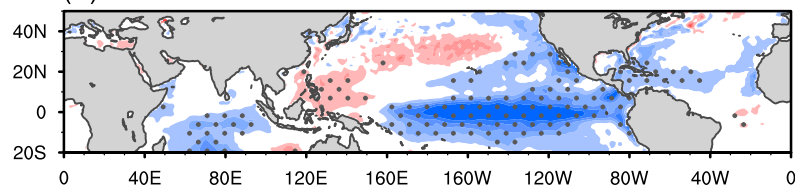

(d) Mar

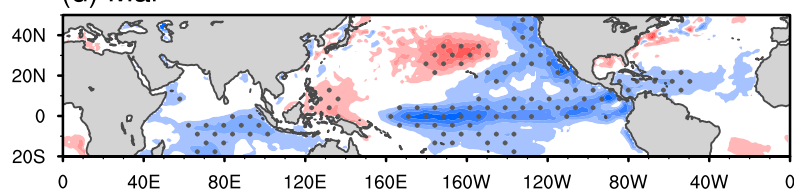

(f) May

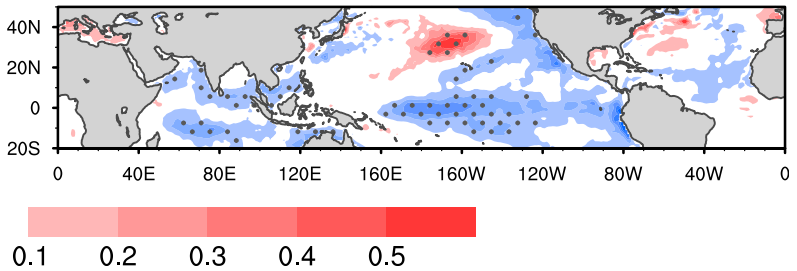

FIG. 10. Lead-lag regression coefficients of monthly mean SST in (a) December-(f) May against DT in March. Stippled areas are significant at the $95 \%$ confidence level.

oceans due to weaker oceanic heat storage rate amplify the land-sea thermal contrast.

Based on the attribution analysis, it is found that the most effective modulator is the land-ocean heat storage, which is closely tied to the variation of soil moisture over the Indochina Peninsula. The precipitation in late February directly affects soil moisture, and therefore may be used as a precursory signal for the interannual variations of $D T$ in March and the onset timing of SCSSM. At longer time scales, when $D T$ is larger, a robust La Niñalike pattern persists from January to April. Thus, the SST anomalies in previous winter can also be treated as a precursory indicator for the variation of surface thermal contrast in March.

Acknowledgments. We are thankful to the three anonymous reviewers who provided constructive comments for improving the overall quality of this paper. The monthly mean precipitation used in this study is the CMAP Precipitation data provided by the NOAA/ OAR/ESRL PSD. The ERA-Interim data were provided by the European Centre for Medium-Range Weather Forecasts. The study was supported by the National Key Research and Development Program of China (2016YFA0602703), the National Natural Science Foundation of China (41690123, 41690120, 91637208, and 41661144019), the Science and Technology Program of Guangzhou (201607010153), the "111-Plan" Project of China (B17049), the Jiangsu Collaborative Innovation Center for Climate Change, and the Guangzhou Joint Research Center for Atmospheric
Sciences of CMA. Yi Deng is supported by the National Science Foundation (AGS-1354402 and AGS1445956) and the National Oceanic and Atmospheric Administration (NA16NWS4680013).

\section{REFERENCES}

Cai, M., and J.-H. Lu, 2009: A new framework for isolating individual feedback processes in coupled general circulation climate models. Part II: Method demonstrations and comparisons. Climate Dyn., 32, 887-900, https://doi.org/10.1007/s00382-008-0424-4.

Chen, T. C., and J. Chen, 1995: An observational study of the South China Sea monsoon during the 1979 summer: Onset and life cycle. Mon. Wea. Rev., 123, 2295-2318, https://doi.org/10.1175/ 1520-0493(1995)123<2295:AOSOTS > 2.0.CO;2.

Dee, D. P., and Coauthors, 2011: The ERA-Interim reanalysis: Configuration and performance of the data assimilation system. Quart. J. Roy. Meteor. Soc., 137, 553-597, https://doi.org/ 10.1002/qj.828.

Deng, Y., T. Park, and M. Cai, 2013: Radiative and dynamical forcing of the surface and atmospheric temperature anomalies associated with the northern annular mode. J. Climate, 26, 5124-5138, https://doi.org/10.1175/JCLI-D-12-00431.1.

Ding, Y., and J. C. L. Chan, 2005: The East Asian summer monsoon: An overview. Meteor. Atmos. Phys., 89, 117-142, https:// doi.org/10.1007/s00703-005-0125-z.

- C. Li, and Y. Liu, 2004: Overview of the South China sea monsoon experiment. Adv. Atmos. Sci., 21, 343-360, https:// doi.org/10.1007/BF02915563.

Gao, H., J. He, Y. Tan, and J. Liu, 2001: Definition of 40-year onset date of South China Sea summer monsoon. J. Nanjing Inst. Meteor., 24, 379-383, https://doi.org/10.3969/J.ISSN.16747097.2001.03.012.

Ha, K.-J., K.-Y. Heo, S.-S. Lee, K.-S. Yun, and J.-G. Jhun, 2012: Variability in the East Asian monsoon: A review. Meteor. Appl., 19, 200-215, https://doi.org/10.1002/met.1320. 
He, B., Y. Zhang, T. Li, and W. Hu, 2017: Interannual variability in the onset of the South China Sea summer monsoon from 1997 to 2014. Atmos. Ocean. Sci. Lett., 10, 73-81, https://doi.org/ 10.1080/16742834.2017.1237853.

He, H., J. McGinnis, Z. Song, and M. Yanai, 1987: Onset of the Asian monsoon in 1979 and the effect of the Tibetan Plateau. Mon. Wea. Rev., 115, 1966-1995, https://doi.org/10.1175/15200493(1987)115<1966:OOTASM>2.0.CO;2.

He, J., and Z. Zhu, 2015: The relation of South China Sea monsoon onset with the subsequent rainfall over the subtropical East Asia. Int. J. Climatol., 35, 4547-4556, https://doi.org/10.1002/ joc. 4305 .

Lau, K.-M., and S. Yang, 1997: Climatology and interannual variability of the Southeast Asian summer monsoon. Adv. Atmos. Sci., 14, 141-162, https://doi.org/10.1007/s00376-997-0016-y.

Li, C., and M. Yanai, 1996: The onset and interannual variability of the Asian summer monsoon in relation to land-sea thermal contrast. J. Climate, 9, 358-375, https://doi.org/10.1175/15200442(1996)009<0358:TOAIVO > 2.0.CO;2.

- and J. Wu, 2000: On the onset of the South China Sea summer monsoon in 1998. Adv. Atmos. Sci., 17, 193-204, https:// doi.org/10.1007/s00376-000-0003-z.

Li, Y., S. Yang, Y. Deng, X. Hu, and M. Cai, 2018: A process-level attribution of the annual cycle of surface temperature over the Maritime Continent. Climate Dyn., 51, 2759-2772, https:// doi.org/10.1007/S00382-017-4043-9.

Liu, B., C. Zhu, Y. Yuan, and K. Xu, 2016: Two types of interannual variability of South China sea summer monsoon onset related to the SST anomalies before and after 1993/94. J. Climate, 29, 6957-6971, https://doi.org/10.1175/JCLI-D-16-0065.1.

Liu, X. F., Q. Li, J. He, and P. Wang, 2010: Effects of the thermal contrast between Indochina Peninsula and South China Sea on the SCS monsoon onset. Acta Meteor. Sin., 24, 459-467.

Liu, Y. M., J. C. L. Chan, J. Mao, and G. Wu, 2002: The role of Bay of Bengal convection in the onset of the 1998 South China Sea. Mon. Wea. Rev., 130, 2731-2744, https://doi.org/10.1175/15200493(2002)130<2731:TROBOB > 2.0.CO;2.

Lu, E., and J. C. L. Chan, 1999: A unified monsoon index for South China. J. Climate, 12, 2375-2385, https://doi.org/10.1175/15200442(1999)012<2375:AUMIFS > 2.0.CO;2.

Lu, J., and M. Cai, 2009: A new framework for isolating individual feedback process in coupled general circulation climate models. Part I: Formulation. Climate Dyn., 32, 873-885, https://doi.org/10.1007/s00382-008-0425-3.

Mao, J., and J. C. Chan, 2005: Intraseasonal variability of the South China Sea summer monsoon. J. Climate, 18, 2388-2402, https://doi.org/10.1175/JCLI3395.1.

, and M. Wang, 2018: The 30-60-day intraseasonal variability of sea surface temperature in the South China Sea during
May-September. Adv. Atmos. Sci., 35, 550-566, https:// doi.org/10.1007/s00376-017-7127-x.

Oh, H., K.-J. Ha, and A. Timmermann, 2018: Disentangling impacts of dynamic and thermodynamic components on late summer rainfall anomalies in East Asia. J. Geophys. Res., 123, 8623-8633, https://doi.org/10.1029/2018JD028652.

Tao, S., and L. Chen, 1987: A review of recent research on the East Asian summer monsoon in China. Monsoon Meteorology, C.-P. Chang and T. N. Krishnamurti, Eds., Oxford University Press, 60-92.

Wang, B., and LinHo, 2002: Rainy season of the Asian-Pacific summer monsoon. J. Climate, 15, 386-398, https://doi.org/ 10.1175/1520-0442(2002)015<0386:RSOTAP > 2.0.CO;2.

,$- \ldots$, Y. Zhang, and M. M. Lu, 2004: Definition of South China Sea monsoon onset and commencement of the East Asian summer monsoon. J. Climate, 17, 699-710, https:// doi.org/10.1175/2932.1.

Wu, G., and Y. Zhang, 1998: Tibetan Plateau forcing and the timing of the monsoon onset over South Asia and the South China Sea. Mon. Wea. Rev., 126, 913-927, https://doi.org/10.1175/ 1520-0493(1998)126<0913:TPFATT >2.0.CO;2.

Wu, R., 2010: Subseasonal variability during the South China Sea summer monsoon onset. Climate Dyn., 34, 629-642, https:// doi.org/10.1007/s00382-009-0679-4.

_ - and B. Wang, 2001: Multi-stage onset of summer monsoon over the western North Pacific. Climate Dyn., 17, 277-289, https://doi.org/10.1007/s003820000118.

Xie, A., Y.-S. Chung, X. Liu, and Q. Ye, 1998: The interannual variations of the summer monsoon onset over the South China Sea. Theor. Appl. Climatol., 59, 201-213, https://doi.org/ 10.1007/s007040050024.

Yan, J., 1997: Observational study on the onset of the South China Sea southwest monsoon. Adv. Atmos. Sci., 14, 277-287, https:// doi.org/10.1007/s00376-997-0026-9.

Yang, S., and K. M. Lau, 1998: Influences of sea surface temperature and ground wetness on Asian summer monsoon. J. Climate, 11, 3230-3246, https://doi.org/10.1175/1520-0442(1998)011<3230: IOSSTA $>2.0 . \mathrm{CO} ; 2$.

Zhang, Q., G. Wu, and Y. Qian, 2002: The bimodality of the $100 \mathrm{hPa}$ South Asia High and its relationship to the climate anomaly over East Asia in summer. J. Meteor. Soc. Japan, 80, 733-744, https://doi.org/10.2151/jmsj.80.733.

Zhou, W., J. C. L. Chan, and C. Li, 2005: South China Sea summer monsoon onset in relation to the off-equatorial ITCZ. Atmos. Adv. Sci., 22, 665-676, https://doi.org/10.1007/ BF02918710.

Zhu, Z., and T. Li, 2017: Empirical prediction of the onset dates of South China Sea summer monsoon. Climate Dyn., 48, 16331645, https://doi.org/10.1007/s00382-016-3164-x. 